\title{
TKA following high tibial osteotomy versus primary TKA - a matched pair analysis
}

\author{
Turgay Efe ${ }^{1^{*}}$, Thomas J Heyse ${ }^{1}$, Christoph Boese ${ }^{1}$, Nina Timmesfeld ${ }^{2}$, Susanne Fuchs-Winkelmann ${ }^{1}$, Jan Schmitt ${ }^{1}$, \\ Christina Theisen ${ }^{1}$, Markus D Schofer ${ }^{1}$
}

\begin{abstract}
Background: High tibial osteotomy (HTO) is a well established technique for the treatment of medial osteoarthritis of the knee with varus malalignment. Results of total knee arthroplasty (TKA) after previous HTO are still discussed controversially. The aim of this study was to elucidate the clinical and radiological results as well as perioperative data of prior HTO on TKA.
\end{abstract}

Methods: Forty-one TKA after HTO were compared to 41 primary TKA at minimum of six years follow-up. Patients were matched according to age, gender, follow-up, etiology, and prosthetic design. Surgical data and complications were evaluated. Clinical outcome was assessed using a number of clinical scores and the visual analogue scale (VAS) for pain. X-rays were evaluated by the method of the American Knee Society. The patellar position was measured by the Insall-Salvati ratio.

Results: There was no significant difference in mean operation time $(p=0.47)$ and complication rate $(p=0.08)$. The Knee Score of the KSS ( $p=0.0007)$ and the ROM ( $p=0.006$ for extension and $p=0.004$ for flexion, respectively) were significantly better in the control group. Mid-term results of the VAS, WOMAC, Lequesne, UCLA, Feller's Patellar Score and SF-36 showed no significant difference. Femoral and tibial component alignment were similar in both groups. One tibial component showed suspect radiolucencies in the HTO group. The Insall-Salvati ratio showed three patients with patella alta and one patient with patella baja in the HTO group. At latest followup all implants were still in place.

Conclusions: Evaluating the clinical and radiological outcome, significant differences were only detected for range of motion and the Knee Score of the KSS. The present study suggests that the results of TKA with and without prior HTO are mainly identical. Although patients with a previous HTO had more complications, no statistically significant differences were noted with this group size.

\section{Background}

According to the Swedish arthroplasty register [1] the number of surgical interventions due to osteoarthritis $(\mathrm{OA})$ of the knee in younger patients $(<55$ years $)$ has doubled in the last decade. High tibial osteotomy (HTO) is a proven treatment option for osteoarthritis of the medial compartment. Although the short-term followup success of tibial osteotomy has shown good clinical outcome, the results seem to gradually deteriorate over time [2-4]. Corresponding to the demographic transition towards a higher average age in our society, more

\footnotetext{
*Correspondence: efet@med.uni-marburg.de

'Department of Orthopaedics and Rheumatology, University Hospital

Marburg, Baldingerstrasse, 35043 Marburg, Germany

Full list of author information is available at the end of the article
}

patients may require total knee arthroplasty (TKA) after failed osteotomy. Primary TKA is a popular and well established method for treatment of advanced degenerative joint disease with survival rates of 90 to $95 \%$ at 10 to 15 years [5-7]. There is evidence that TKA after previous $\mathrm{HTO}$ is technically more difficult and implies greater risk of complications than primary TKA $[8,9]$. Great debate whether a previously performed HTO may influence the clinical and radiological outcome of later TKA is still on-going. Several authors reported that previous HTO makes minimal or no difference [10-12] in the outcome of TKA while others showed poorer results $[9,13,14]$.

The aim of the present study was twofold. In the first part of the study surgical data and clinical outcome of 
TKA after a previous HTO were compared with a cohort of patients who had undergone a primary TKA. In the second part of the study the radiological outcome of TKA after a previous HTO was compared with the control group.

\section{Methods}

In a retrospective approach, 1519 cases of TKA performed between 1998 and 2003 at the authors' institution were identified from medical records. Among these cases there were 41 patients requiring surgery after previous HTO. Groups were matched according to age, gender, follow-up, etiology and prosthetic design. According to Rand et al. [15] there is a hazard ratio for each of the risk factors gender, age, etiology, prosthesis design and follow-up. Using the log hazard ratio, the beta-value can be recalculated. By adding the beta values of the different risk factors for each patient, an individual risk score is obtained. Subsequently, partners within the groups of minimal follow-up time differences with nearly identical risk factors were matched. Allocation of matched pairs was performed within an interval of $+/-3$ months of follow-up time. By this method the risk factors are compared in the overall context according to their relevance expressed by their hazard ratio. The study was authorised by the local ethical committee (No. 95/07).

The HTO group included 21 male and 20 female patients and the control group 17 male and 24 female patients. The average age at tibial osteotomy was $53 \pm 4$ (42-60) years. The mean time interval between HTO and TKA was $86 \pm 19(60-130)$ months. The average age at the time of examination was $69 \pm 8$ (51-84) years in the HTO group and $73 \pm 7$ (55-85) years in the control group. Follow-up examination following TKA was performed after an average of $82 \pm 22$ (48-121) months in the HTO group and after an average of $85 \pm 20$ (50-121) months in the control group.

The indication for HTO was symptomatic medial compartment osteoarthritis with varus malalignment. The conversion from HTO to TKA included radiographic progression of the osteoarthritis and increasing pain. In the HTO and control group primary degenerative osteoarthritis was seen in 40 patients, and rheumatoid arthritis in 1 patient. It is accepted that HTO is contraindicated in subjects with inflammatory arthritis but the diagnosis had been detected after the osteotomy. HTO was performed in 22 cases on the right and 19 on the left side. 20 primary TKA were performed on the right and 21 on the left side. All patients were operated on using the lateral closing-wedge technique as popularised by Coventry [16]. Fibular transection was performed at the junction of the middle and distal thirds [17], through a separate incision. A transverse incision with the patient in supine position was performed for the tibial osteotomy. Peroneal nerve was exposed and protected. The osteotomy was performed below the tibial tuberosity leaving the medial cortex intact. The bone wedge size was based on the preoperative calculations from the long leg standing radiograph. A laterallybased wedge of bone was removed and the osteotomy was fixed with an AO-plate.

In all cases hardware removal through the same incision was performed after 1 year when bony consolidation of the osteotomy was completed. The indication for primary TKA occurred due to a considerable increase of osteoarthritis and pain. A cemented posterior-stabilised prosthesis (NexGen LPS, Zimmer, Warsaw, IN, USA) was implanted in all cases (Fig. 1). After a midline skin incision, the standard medial parapatellar capsular approach was used in all cases. Patellar resurfacing was not undertaken.

The clinical results were evaluated by the Western Ontario and McMaster Universities (WOMAC) Osteoarthritis Index [18], Visual Analog Scale (VAS), Knee Society Score (KSS) [19], Lequesne Index [20] and University of California Los Angeles Activity Assessment (UCLA) [21], as well as Feller's Patellar Score [22] and Medical Outcomes Study Short-Form 36 (SF-36) Health Survey [23] at the final follow-up. The ROM of the knee was measured using a goniometer. Standardised conventional X-rays in antero-posterior, lateral and skyline view of the patella in $30^{\circ}$ flexion were taken. The radiological results were examined by the radiographic evaluation method of the American Knee Society [24]. Thereby the positioning of the prosthetic components was evaluated by measuring specific angles $(\alpha, \beta, \gamma, \delta)$ in relation to the anatomical femoro-tibial axes and radiolucent lines. The femoral and tibial components were divided into seven zones in the antero-posterior and lateral view, the tibial component into three zones in the lateral view. The numerical score for the components was determined by measuring the width of the radiolucent lines for each of the zones in millimetres. For a seven-zone component, a score of 4 or less is regarded as stable, a score between 5 and 9 should be monitored for possible progression, and 10 or more indicates loosening. Patellar height was measured according to Insall-Salvati (IS) ratio [25]. All patients were investigated by a physical examination and the application of clinical scores by co-author CB, an orthopaedic resident. An independent specialist in radiology evaluated the diagnostic images. All of the osteotomies and arthroplasties were performed by two surgeons. The operating surgeons were not involved in the clinical assessment.

\section{Statistical analysis}

The outcome of TKA after HTO was compared with primary TKA using the Welch's two-sample t-test. The 


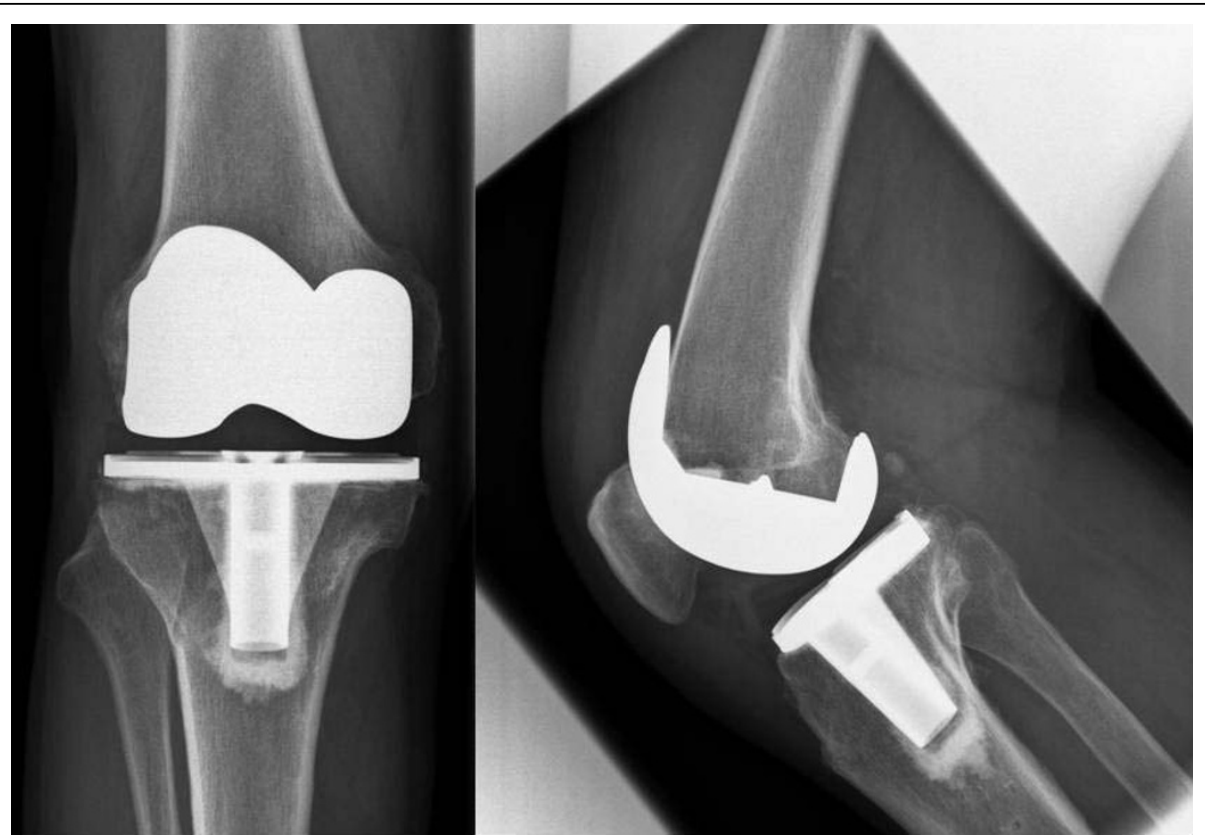

Figure 1 Implantation of a NexGen LPS TKA after previous closed-wedge osteotomy. The roentgenograms at the latest follow-up show good alignment and patella baja.

comparison of the complication rate was performed with the Fisher's exact test. The level of significance was defined as $\mathrm{P}<0.05$.

\section{Results}

The mean operation time showed no statistically significant difference $(\mathrm{p}=0.47)$ between the HTO group with $95 \pm 14$ (75-115) minutes and the control group with 90 \pm 11 (65-105) minutes. The HTO group required three lateral releases, one medial tightening and four synovectomies compared to four synovectomies in the control group. Eight complications (19.5\%) were noticed in the HTO group: four cases of skin necrosis at the proximal part of the tibia required revision, two stiff knees (flexion $<90^{\circ}$ ) required mobilisation under general anaesthesia, one superficial infection could be managed with antibiotics and there was one clinically apparent venous thrombosis. In the control group, two (4.8\%) superficial infections responded to antibiotics. No significant difference was detected between the two groups with respect to complications $(\mathrm{p}=0.08)$. Neurovascular injuries, delayed union and non-union, compartment syndrome and intra-articular fractures associated with HTO did not occur. There were no cases of deep infections in both groups.

Patients who had undergone a previous osteotomy showed less ROM. The mean extension and mean flexion was $1.7^{\circ} \pm 3.1^{\circ}\left(0^{\circ}-10^{\circ}\right)$ and $106^{\circ} \pm 14.1\left(55^{\circ}-125^{\circ}\right)$ in the HTO group, and $0.2^{\circ} \pm 1.1^{\circ}\left(0^{\circ}-5^{\circ}\right)$ and $115^{\circ} \pm 13.2$ $\left(90^{\circ}-140^{\circ}\right)$ in the control group, respectively. These differences were statistically significant $(\mathrm{p}=0.006$ and $\mathrm{p}=0.004$, respectively). The mean VAS score in both groups was $1.2(\mathrm{p}=0.96)$. The results of the SF-36, Feller, Lequesne, KSS, UCLA and WOMAC scores are shown in Table 1. Except the worse knee score of the KSS in the HTO group ( $p=0.0007)$, the overall clinical outcome showed no significant difference with a trend in favour of the control group.

The radiographic assessments of both groups are given in Table 2. No significant difference for femoral and tibial component positioning was noticed between the two groups. In the HTO group 10 femoral and 5 tibial components showed small non-progressive radioluncencies, whereas in the control group 6 femoral and 5 tibial components had small non-progressive radioluncencies. A significant difference in radiolucencies could not be detected between the groups. Suspect radiolucencies were only present in one tibial component $(5 \mathrm{~mm})$ in the HTO group but the patient had no clinical symptoms. No suspect radiolucencies were seen in the control group. No component had to be revised. In the HTO group the mean IS ratio was $0.94 \pm 0.17$ (0.85-1.3) $\mathrm{mm}$, and patients in the control group showed a mean IS ratio of $0.90 \pm 0.15(0.8-1.2) \mathrm{mm}(\mathrm{p}=0.34)$. There were more outliers in the HTO group with three cases of patella alta and one case of patella baja.

\section{Discussion}

The most important finding of the present study is that the outcome of primary TKA and TKA following HTO 
Table 1 Clinical scores

\begin{tabular}{|c|c|c|c|c|}
\hline Scores & & HTO group & Control group & P-value \\
\hline WOMAC (0-100) & Pain & $14.8 \pm 19.4(0-70)$ & $16.4 \pm 24.1(0-86)$ & 0.74 \\
\hline \multirow[t]{2}{*}{ higher scores indicates difficulties } & Stiffness & $15.2 \pm 17.2(0-60)$ & $21.1 \pm 24.7(0-90)$ & 0.22 \\
\hline & Function & $18 \pm 18.2(0-61)$ & $21.3 \pm 23.7(0-84))$ & 0.49 \\
\hline KSS (0-100) & Knee & $78.8 \pm 18.9(37-100)$ & $91 \pm 11.0(54-100)$ & 0.0007 \\
\hline 0 poor- 100 excellent & Function & $78.2 \pm 21.1(25-100)$ & $87.8 \pm 48.3(35-100)$ & 0.25 \\
\hline Lequesne (0-8) & Pain or discomfort & $2 \pm 1.8(0-6)$ & $2.1 \pm 1.8(0-8)$ & 0.61 \\
\hline \multirow[t]{2}{*}{1 mild, $>14$ severe discomfort } & Maximum distance walked & $1.4 \pm 1(0-5)$ & $1.4 \pm 1(0-5)$ & 0.21 \\
\hline & Activities of daily living & $2 \pm 1.7(0-7)$ & $2.4 \pm 2.3(0-8)$ & 0.21 \\
\hline $\begin{array}{l}\text { UCLA (1-10) } \\
1 \text { low-10 high activity }\end{array}$ & & $5.7 \pm 1.2(2-7)$ & $5.3 \pm 1.4(2-7)$ & 0.16 \\
\hline $\begin{array}{l}\text { Feller's Patellar Score (3-30) } \\
3 \text { poor- } 30 \text { excellent }\end{array}$ & & $25.9 \pm 6.2(6-30)$ & $26.5 \pm 4.8(11-30)$ & 0.61 \\
\hline SF-36 (0-100) & Physical functioning & $64.3 \pm 28.9(0-100)$ & $56.1 \pm 31(10-100)$ & 0.22 \\
\hline \multirow[t]{7}{*}{0 poor-100 good health } & Role-physical & $59.8 \pm 44.7(0-100)$ & $58.5 \pm 45.6(0-100)$ & 0.90 \\
\hline & Pain index & $59.9 \pm 20.4(12-100)$ & $52.4 \pm 23.1(20-82)$ & 0.12 \\
\hline & General health perception & $67.1 \pm 21.7(10-107)$ & $69.3 \pm 24.1(30-107)$ & 0.66 \\
\hline & Vitality & $58.7 \pm 20.2(0-95)$ & $52.6 \pm 26.4(10-100)$ & 0.24 \\
\hline & Social functioning & $63.4 \pm 20.8(0-875)$ & $58.5 \pm 18.4(25-87)$ & 0.26 \\
\hline & Role-emotional & $77.2 \pm 37.6(0-100)$ & $69.1 \pm 43.7(0-100)$ & 0.37 \\
\hline & Mental health index & $75.1 \pm 18.3(0-96)$ & $67.7 \pm 24.1(8-100)$ & 0.12 \\
\hline
\end{tabular}

The values are listed as mean, with standard deviation and range. Significant difference is given in bold.

as recorded by clinical and radiological results were quite similar. Even though patients with previous HTO had more postoperative complications the difference was not statistically significant.

The present study has some limitations mainly due to its retrospective design. However, matched-pair analyses allow ruling out some bias by matching some of the contributing factors. Of course matching is only possible to a certain extent, limited by patient numbers and availability of data. Other factors that might have influenced the outcome but were not matched are e.g. the ASA classification and obesity. Of major interest is usually the revision rate after joint arthroplasty. Revision rates can not easily be assessed by a matched-pair study. Even though there is sufficient number of studies available on TKA outcomes after HTO, the results in literature show a great variability. Differences in outcome may be caused by wide heterogeneity among the studies and pooling of the results are a challenge, as described by van Raaij et al. [26] in a systematic review. In order to minimise the effect of variables such as age, gender, follow-up, etiology and prosthetic design we compared the results of 41 primary TKA with 41 TKA following closed-wedge HTO in a matched-pair analysis.

HTO is an accepted treatment of varus OA of the knee in active patients. There is some evidence that malalignment induces OA progression and even development. Perhaps correction of malaligment may have a positive effect on OA. Not all HTO patients will require TKA and survival of HTO after 10 years with TKA as an endpoint ranges between 51 and 92\% among several studies [3,27-29]. However, performing TKA secondary to HTO may be related to difficulties. In the present study several interventions had to be done to align the

Table 2 Radiographic assessment according to the Knee Society Roentgenographic Evaluation System

\begin{tabular}{llll}
\hline & HTO group & Control group & P-value \\
\hline Femoral component flexion a-p $(\alpha)$ & $97^{\circ} \pm 3.1^{\circ}\left(92^{\circ}-102^{\circ}\right)$ & $97^{\circ} \pm 3.2^{\circ}\left(91^{\circ}-104^{\circ}\right)$ & 0.76 \\
Tibial component angle a-p $(\beta)$ & $87^{\circ} \pm 1.7^{\circ}\left(82^{\circ}-92^{\circ}\right)$ & $87^{\circ} \pm 2.1^{\circ}\left(81^{\circ}-93^{\circ}\right)$ & 0.86 \\
Femoral component flexion lat $(\gamma)$ & $4.7^{\circ} \pm 2.7^{\circ}\left(0^{\circ}-10^{\circ}\right)$ & $5^{\circ} \pm 2.3^{\circ}\left(0^{\circ}-9^{\circ}\right)$ & 0.69 \\
Tibial component angle lat $(\delta)$ & $84^{\circ} \pm 1.4^{\circ}\left(77^{\circ}-90^{\circ}\right)$ & $82^{\circ} \pm 1^{\circ}\left(73^{\circ}-93^{\circ}\right)$ & 0.15 \\
Loosening of the components & & & \\
Femoral lat (mm) & $\mathrm{n}=4(1) ; 3(2) ; 1(3) ; 2(4)$ & $\mathrm{n}=2(1) ; 4(2)$ & 0.50 \\
Tibial a-p and lat $(\mathrm{mm})$ & $\mathrm{n}=4(1) ; 1(4) ; 1(5)$ & $\mathrm{n}=2(1) ; 3(2)$ & 0.17 \\
\hline
\end{tabular}

The values of the specific angles are listed as mean, with standard deviation and range. Suspicious radiolucencies $(5 \mathrm{~mm})$ were noted in one tibial component in the HTO group. a-p: anteroposterior view, lat: lateral view. 
patella in the HTO group. This did not prolong TKA significantly. The small difference in operation time is in contrast to other studies $[14,30,31]$ with more technical difficulties in exposure of the proximal part of the tibia, altered anatomy and soft tissue imbalance. The complication rate in the HTO group was considerably higher than described by Cameron and Park [32] and Madan et al. [14] with $11.2 \%$ and $9.7 \%$, respectively. This may be related to the various risk factors of the patients.

Even though almost all clinical scores showed no significant differences between both groups, there seems to be trend in favour of the control group. In contrast to other studies [11,12,33-35] there were significant differences in Part A of the KSS in disfavour of the HTO group. Probably this can be explained by the poorer range of motion. A systematic review by van Raaij et al. [26] showed less range of motion with a median of $10^{\circ}$ in patients receiving TKA following HTO compared to patients with primary TKA. However, Miner et al. [36] revealed that for assessment of TKA outcome ROM is much less important than the overall results.

Mode of failure in TKA includes osteolysis, malaligment, or malpositioning [37]. In the present study suspect radiolucencies were only present in one tibial component. Haslam et al. [38] could demonstrate that most TKA failures tend to occur after 6 years or more. The mean follow-up of the present study was slightly longer than 7 years, a conclusion about loosening is therefore only possible to a certain extent. As observed by several authors $[35,39,40]$ we were unable to show significant differences in migration, alignment, or positioning of the TKA components between the two groups. In contrast to our results, Parvizi et al. [9] noticed in a retrospective study about the risk factors for failure of TKA after previous HTO a high rate of femoral and tibial component loosening. They concluded that a reason for this may be that patients who had undergone a HTO are commonly younger and more obese. As a limitation they used matched control patients only for patients with bilateral TKA after a history of HTO, but did not use for all patients. Similar results were published by Kazakos et al. [31], and even though they recorded significant differences particularly in the radiographic evaluation after HTO, this did not compromise the clinical results.

Most data in literature as well as in the present study fail to detect considerable differences between subjects treated with TKA following HTO or primary TKA. In summary there seems to be a lack of randomised controlled trials. Well designed studies should investigate large numbers of subjects to generate higher quality of evidence. Furthermore, long-term results are needed to reach more solid conclusions.

\section{Conclusions}

Although the results of clinical scores and radiological evaluation were quite similar in both groups patients after prior HTO showed significantly less range of motion. Surgeons should be aware that TKA is more challenging after HTO and was associated with more postoperative complications in the present study. However, satisfactory results with good survival can be achieved at mid-term follow-up.

\section{Acknowledgements}

The authors wish to thank Dr. Johanna Schmitt for editing the manuscript and help with the English language.

\section{Author details}

${ }^{1}$ Department of Orthopaedics and Rheumatology, University Hospital Marburg, Baldingerstrasse, 35043 Marburg, Germany. ${ }^{2}$ Institute of Medical Biometry and Epidemiology, Philipps-University Marburg, Bunsenstrasse 3, 35037 Marburg, Germany.

\section{Authors' contributions}

TE drafted the manuscript, and participated in its design and coordination; CB investigated, followed up and managed the patient, NT performed the statistical analysis; TJH, SFW, JS and CT participated in analysis and interpretation of data, MDS initiated the study, and participated in its design and coordination. All authors read and approved the final manuscript.

\section{Competing interests}

The authors declare that they have no competing interests.

Received: 27 May 2010 Accepted: 14 September 2010 Published: 14 September 2010

\section{References}

1. W-Dahl A, Robertsson O, Lidgren L: Surgery for knee osteoarthritis in younger patients. Acta Orthop 2010, 81(2):161-164.

2. Gstottner M, Pedross F, Liebensteiner M, Bach C: Long-term outcome after high tibial osteotomy. Arch Orthop Trauma Surg 2008, 128(1):111-115.

3. Papachristou G, Plessas S, Sourlas J, Levidiotis C, Chronopoulos E, Papachristou C: Deterioration of long-term results following high tibial osteotomy in patients under 60 years of age. Int Orthop 2006, 30(5):403-408.

4. Virolainen P, Aro HT: High tibial osteotomy for the treatment of osteoarthritis of the knee: a review of the literature and a meta-analysis of follow-up studies. Arch Orthop Trauma Surg 2004, 124(4):258-261.

5. Buechel FF, Buechel FF Jr, Pappas MJ, Dalessio J: Twenty-year evaluation of the New Jersey LCS Rotating Platform Knee Replacement. J Knee Surg 2002, 15(2):84-89.

6. Laskin RS: The Genesis total knee prosthesis: a 10-year followup study. Clin Orthop Relat Res 2001, , 388: 95-102.

7. Robertsson O, Knutson K, Lewold S, Lidgren L: The Swedish Knee Arthroplasty Register 1975-1997: an update with special emphasis on 41,223 knees operated on in 1988-1997. Acta Orthop Scand 2001, 72(5):503-513.

8. Windsor RE, Insall JN, Vince KG: Technical considerations of total knee arthroplasty after proximal tibial osteotomy. J Bone Joint Surg Am 1988, 70(4):547-555.

9. Parvizi J, Hanssen AD, Spangehl MJ: Total knee arthroplasty following proximal tibial osteotomy: risk factors for failure. J Bone Joint Surg Am 2004, 86-A(3):474-479.

10. Bergenudd H, Sahlstrom A, Sanzen L: Total knee arthroplasty after failed proximal tibial valgus osteotomy. J Arthroplasty 1997, 12(6):635-638.

11. Haddad FS, Bentley G: Total knee arthroplasty after high tibial osteotomy: a medium-term review. J Arthroplasty 2000, 15(5):597-603.

12. Meding JB, Keating EM, Ritter MA, Faris PM: Total knee arthroplasty after high tibial osteotomy. A comparison study in patients who had bilateral total knee replacement. J Bone Joint Surg Am 2000, 82(9):1252-1259. 
13. Katz MM, Hungerford DS, Krackow KA, Lennox DW: Results of total knee arthroplasty after failed proximal tibial osteotomy for osteoarthritis. $J$ Bone Joint Surg Am 1987, 69(2):225-233.

14. Madan S, Ranjith RK, Fiddian NJ: Total knee replacement following high tibial osteotomy. Bull Hosp Jt Dis 2002, 61(12):5-10.

15. Rand JA, Trousdale RT, Ilstrup DM, Harmsen WS: Factors affecting the durability of primary total knee prostheses. J Bone Joint Surg Am 2003, 85-A(2):259-265.

16. Coventry MB: Osteotomy about the knee for degenerative and rheumatoid arthritis. J Bone Joint Surg Am 1973, 55(1):23-48.

17. Aydogdu S, Yercan H, Saylam C, Sur H: Peroneal nerve dysfunction after high tibial osteotomy. An anatomical cadaver study. Acta Orthop Belg 1996, 62(3):156-160

18. Bellamy N, Buchanan WW, Goldsmith CH, Campbell J, Stitt LW: Validation study of WOMAC: a health status instrument for measuring clinically important patient relevant outcomes to antirheumatic drug therapy in patients with osteoarthritis of the hip or knee. J Rheumatol 1988, 15(12):1833-1840.

19. Insall JN, Dorr LD, Scott RD, Scott WN: Rationale of the Knee Society clinical rating system. Clin Orthop Relat Res 1989, , 248: 13-14.

20. Lequesne MG, Mery C, Samson M, Gerard P: Indexes of severity for osteoarthritis of the hip and knee. Validation-value in comparison with other assessment tests. Scand J Rheumatol Supp/ 1987, 65:85-89.

21. Zahiri CA, Schmalzried TP, Szuszczewicz ES, Amstutz HC: Assessing activity in joint replacement patients. J Arthroplasty 1998, 13(8):890-895.

22. Feller JA, Bartlett RJ, Lang DM: Patellar resurfacing versus retention in total knee arthroplasty. J Bone Joint Surg Br 1996, 78(2):226-228.

23. Stewart AL, Hays RD, Ware JE Jr: The MOS short-form general health survey. Reliability and validity in a patient population. Med Care 1988, 26(7):724-735

24. Ewald FC: The Knee Society total knee arthroplasty roentgenographic evaluation and scoring system. Clin Orthop Relat Res 1989, 248: 9-12.

25. Insall J, Salvati E: Patella position in the normal knee joint. Radiology 1971, 101(1):101-104

26. van Raaij TM, Reijman M, Furlan AD, Verhaar JA: Total knee arthroplasty after high tibial osteotomy. A systematic review. BMC Musculoskelet Disord 2009, 10:88.

27. Naudie D, Bourne RB, Rorabeck $\mathrm{CH}$, Bourne TJ: The Install Award. Survivorship of the high tibial valgus osteotomy. A 10- to -22-year followup study. Clin Orthop Relat Res 1999, , 367: 18-27.

28. Sprenger TR, Doerzbacher JF: Tibial osteotomy for the treatment of varus gonarthrosis. Survival and failure analysis to twenty-two years. J Bone Joint Surg Am 2003, 85-A(3):469-474.

29. Aglietti $P$, Rinonapoli E, Stringa G, Taviani A: Tibial osteotomy for the varus osteoarthritic knee. Clin Orthop Relat Res 1983, 176: 239-251.

30. Karabatsos B, Mahomed NN, Maistrelli GL: Functional outcome of total knee arthroplasty after high tibial osteotomy. Can J Surg 2002, 45(2):116-119.

31. Kazakos KJ, Chatzipapas C, Verettas D, Galanis V, Xarchas KC, Psillakis I: Midterm results of total knee arthroplasty after high tibial osteotomy. Arch Orthop Trauma Surg 2008, 128(2):167-173.

32. Cameron HU, Park YS: Total knee replacement following high tibial osteotomy and unicompartmental knee. Orthopedics 1996, 19(9):807-808.

33. van Raaij TM, Bakker W, Reijman M, Verhaar JA: The effect of high tibial osteotomy on the results of total knee arthroplasty: a matched case control study. BMC Musculoskelet Disord 2007, 8:74.

34. Huang HT, Su JY, Su KN, Tien YC: Total knee arthroplasty after failed dome osteotomy. Kaohsiung J Med Sci 2002, 18(10):485-491.

35. Amendola L, Fosco M, Cenni E, Tigani D: Knee joint arthroplasty after tibial osteotomy. Int Orthop 34(2):289-295.

36. Miner $A L$, Lingard EA, Wright EA, Sledge CB, Katz JN: Knee range of motion after total knee arthroplasty: how important is this as an outcome measure? J Arthroplasty 2003, 18(3):286-294.

37. Callaghan JJ, O'Rourke M R, Saleh KJ: Why knees fail: lessons learned. J Arthroplasty 2004, 19(4 Suppl 1):31-34

38. Haslam P, Armstrong M, Geutjens G, Wilton TJ: Total knee arthroplasty after failed high tibial osteotomy long-term follow-up of matched groups. J Arthroplasty 2007, 22(2):245-250

39. Bae DK, Song SJ, Yoon KH: Total knee arthroplasty following closed wedge high tibial osteotomy. Int Orthop 34(2):283-287.
40. Toksvig-Larsen S, Magyar G, Onsten I, Ryd L, Lindstrand A: Fixation of the tibial component of total knee arthroplasty after high tibial osteotomy: a matched radiostereometric study. J Bone Joint Surg Br 1998, 80(2):295-297.

\section{Pre-publication history}

The pre-publication history for this paper can be accessed here: http://www.biomedcentral.com/1471-2474/11/207/prepub

doi:10.1186/1471-2474-11-207

Cite this article as: Efe et al:: TKA following high tibial osteotomy versus primary TKA - a matched pair analysis. BMC Musculoskeletal Disorders $201011: 207$.

\section{Submit your next manuscript to BioMed Central and take full advantage of:}

- Convenient online submission

- Thorough peer review

- No space constraints or color figure charges

- Immediate publication on acceptance

- Inclusion in PubMed, CAS, Scopus and Google Scholar

- Research which is freely available for redistribution

Submit your manuscript at www.biomedcentral.com/submit
C) Biomed Central 